\title{
EFFECT OF ANNEALING AND IRRADIATION ON THE OPTICAL PROPERTIES OF OXIDE CRYSTALS
}

\author{
S.M. KaCZMAREK ${ }^{a *}$, M. BerKoWsK ${ }^{b}$, Z. MOROZ ${ }^{c}$ AND S. WARChOL ${ }^{d}$ \\ ${ }^{a}$ Military Univerwity of Technology, Kaliskiego 2, 00-908 Warsaw, Poland \\ ${ }^{b}$ Institute of Plyysics, Polish Academy of Sciences \\ Al. Lotników 32/46, 02-668 Warsaw, Poland \\ "Sottan Institule of Nuclear Studies, 05-400 Otwock-Swierk, Poland

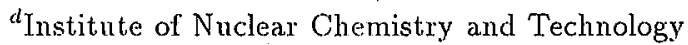 \\ Dorodna 16, 03-195 Warsaw, Poland
}

(Received April 16, 1999; revised version June 25, 1999)

\begin{abstract}
We described results of the effect of annealing and irradiation treatments on the optical properties of $\mathrm{Y}_{3} \mathrm{Al}_{5} \mathrm{O}_{12}, \mathrm{YAIO}_{3}, \mathrm{SrLaGa}_{3} \mathrm{O}_{7}, \mathrm{LiNbO}_{3}$, $\mathrm{Grd}_{3} \mathrm{Ga}_{5} \mathrm{O}_{12}, \mathrm{LaGaO}_{3}, \mathrm{ZnSe}$, and $\mathrm{LiF}$ single crystals. Changes in absorption and luminescence are presented. Recharging processes of uncontrolled impurities (e.g. $\mathrm{Fe}^{3+}, \mathrm{Fe}^{2+}$, and $\mathrm{Mn}^{2+}$ ), and active ions (e.g. $\mathrm{Nd}^{3+}, \mathrm{Dy}^{3+}, \mathrm{Cr}^{4+}$, $\mathrm{Cr}^{3+}$, and $\left.\mathrm{Ce}^{3+}\right)$, as well as types of color centers produced in the crystals after a particular irradiation or annealing treatment are presented.
\end{abstract}

PACS numbers: $61.72 . \mathrm{Ji}, 61.80 . \mathrm{Ed}$

\section{Introduction}

Studies on the influence of the irradiation by various types of ionizing particles on the efficiency of solid state lasers are motivated by a need of using them in many applications, e.g. as range finders, altimeters and others, in intense external radiation fields [1]. On the other hand, a positive influence of the ionizing radiation on the laser performance is also known. In particular, such phenomenon was observed in lasers based on $\mathrm{Cr}, \mathrm{Tm}, \mathrm{Ho}: \mathrm{Y}_{3} \mathrm{Al}_{5} \mathrm{O}_{12}$ and $\mathrm{Er}: \mathrm{Y}_{3} \mathrm{Al}_{5} \mathrm{O}_{12}$ crystals $[2,3]$.

Optical characteristics of other optoelectronic elements and devices based on oxide crystals also changes during their staying inside radiation field. Common methods of characterization of the oxide crystals may not give a precise answer

*Corresponding author; e-mail: skaczmar@wat.waw.pl 
to the question: what is the performance of the devices in conditions of strong external radiation fields.

The aim of this paper is to determine the ability of the method of ionizing radiation treatment of optoelectronic materials to characterize the compounds and, may be, to change their optical properties.

\section{Experimental}

The following crystals were investigated: $\mathrm{Y}_{3} \mathrm{Al}_{5} \mathrm{O}_{12}$ (YAG), $\mathrm{YAlO}_{3}$ (YAP), $\mathrm{SrLaCa}_{3} \mathrm{O}_{7}$ (SLGO), $\mathrm{LiNb}_{3}(\mathrm{LN}), \mathrm{Gd}_{3} \mathrm{Ga}_{5} \mathrm{O}_{12}$ (GGG), $\mathrm{LaGaO}_{3}$ and $\mathrm{ZnSe}$ and LiF. They were obtained in the Institute of Electronic Materials Technology, Institute of Physics of the Polish Academy of Sciences, and Institute of Physics of the Military University of Technology in Warsaw.

Using various ${ }^{60} \mathrm{Co}$ sources the crystals were irradiated by $\gamma$-rays in the Institute of Chemistry and Nuclear Technology (ICNT) in Warsaw and the Institute of Atomic Energy in Świerk, Poland. For the electron irradiation a $300 \mathrm{keV}$ or $1 \mathrm{MeV}$ beams from the Van de Graaf accelerator of the ICNT were used, while for irradiation with $21 \mathrm{MeV}$ protons a beam from compact isochronous proton cyclotron installed in the Sottan Institute of Nuclear Studies, Świerk, was applied.

The dose of $\gamma$-irradiation was varied from $10^{2}$ to $10^{7} \mathrm{~Gy}$, fluency of electrons was varied from $10^{14}$ to $5 \times 10^{16}$ particles $/ \mathrm{cm}^{2}$, and protons fluences from $5 \times 10^{12}$ to $10^{16}$ particles $/ \mathrm{cm}^{2}$ were applied.

Annealing was performed in three regimes: (i) thermal relaxation by annealing in air at $400^{\circ} \mathrm{C}$ for $\mathrm{YAG}$ and at $800^{\circ} \mathrm{C}$ for $\mathrm{LN}$, for $3 \mathrm{~h}$ in order to remove radiation defects, (ii) annealing at $1400^{\circ} \mathrm{C}$ (or $1100^{\circ} \mathrm{C}$ ) for $3 \mathrm{~h}$ in air (an oxidizing atmosphere) in order to change the defect structure of a crystal, and (iii) annealing in a mixture of hydrogen and nitrogen (a reducing a.mosphere) at $1200^{\circ} \mathrm{C}$ for $0.5 \mathrm{~h}$.

Optical transmission spectra were recorded before and after each irradiation or thermal treatment of the samples using LAMBDA-2 Perkin-Elmer, ACTA VII Beckman and FTIR 1725 Perkin-Elmer spectrophotometers. The induced additional absorption (AA) was calculated from the formula

$$
\Delta K=(1 / d) \ln \left(T_{1} / T_{2}\right),
$$

where $K$ is the absorption, $d$ is the sample thickness, and $T_{1}$ and $T_{2}$ are the optical transmissions of a sample before and after irradiation or annealing treatment, respectively.

\section{Results and discussion}

\subsection{Absorption}

Figure 1 shows additional absorption of Cr doped SLGO (Fig. 1a) and Pr, Er, and Nd doped YAP (Fig. 1b, c) crystals after four different kinds of treatments: $\gamma$-irradiation of as-grown crystals (Fig. 1a, curve 2 ; Fig. 1 b, curve 1 ; Fig. $1 \mathrm{c}$, curves 1 and 2), annealing of as-grown crystals in air (Fig. 1a, curve 1; Fig. 1b, curve 3), annealing in reducing atmosphere (Fig. 1b, curve 2) and proton irradiation (Fig. 1a, curve 3; Fig. 1c, curve 3). 


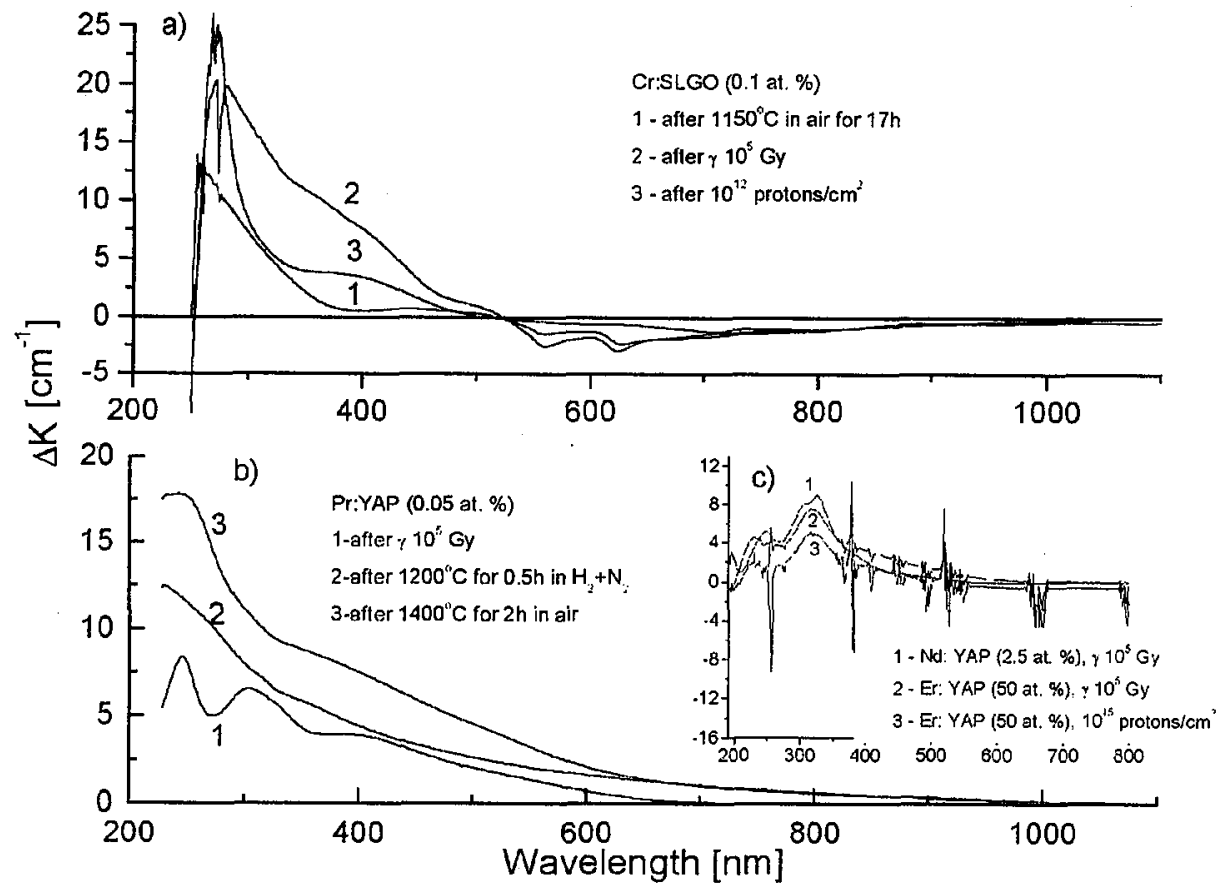

Fig. 1. AA bands in (a) Cr:SLGO after: (1) $1150^{\circ} \mathrm{C}$ annealing in air for $17 \mathrm{~h}$, (2) $10^{5}$ Gy irradiation with $\gamma$-rays, and (3) $10^{12} \mathrm{~cm}^{-2}$ irradiation with protons, (b) Pr:YAP after (1) $10^{5}$ Gy irradiation with $\gamma$-rays, (2) $1200^{\circ} \mathrm{C}$ annealing in $\mathrm{H}_{2}+\mathrm{N}_{2}$ mixture for $0.5 \mathrm{~h}$, and (3) $1400^{\circ} \mathrm{C}$ annealing in air for $2 \mathrm{~h}$, and (c) Nd:YAP irradiated with $\gamma$-rays with a dose of $10^{5} \mathrm{~Gy}$ (1) and Er:YAP for different types of treatments: (2) $\gamma$-rays with a dose of $10^{5} \mathrm{~Gy}$, and (3) protons with a fluency of $10^{15} \mathrm{~cm}^{-2}$.

For both types of crystals (YAP and SLGO) a large additional absorption (large $\Delta K$ values) is seen after different treatments. As is seen from Fig. la, the influence of temperature (annealing in air) and ionizing rays (gamma and protons) on the absorption spectrum of Cr:SLGO crystal is of the same type in the range of Cr transitions (500-800 $\mathrm{mm}$ ). Negative value of AA in this range suggests that ionization of active $\mathrm{Cr}^{3+}$ ions takes place during both types of treatments, resulting in an increase in concentration of $\mathrm{Cr}^{4+}$ ions. However, these two types of treatments differ from each other in producing radiation defects.

Irradiation with gamma and proton rays leads to an increase in AA in color center (CC) region with a maximum at about $380 \mathrm{~nm}$ but gamma gives larger $A A$ values. As was found earlier [4], this CC is associated with oxide vacancies in Cr:SLGO single crystal. Moreover, for both types of the above named treatments the AA band appears at about $270 \mathrm{~nm}$. This $\mathrm{CC}$ is attributed to $\mathrm{Ga}^{3+} \rightarrow \mathrm{Ga}^{2+}$ reaction leading to the shift of a short-wave absorption edge [4].

Figure $1 \mathrm{~b}$ shows that annealing of Pr:YAP crystal in different atmospheres leads to AA bands comparable to that which occur after $\gamma$-rays irradiation. Usually, additional absorption occurring after annealing and irradiation (especially, for 
annealing performed after irradiation) have opposite values. Annealing in air leads to an increase in the valency of uncontrolled or active impurity, while gamma irradiation and annealing in reducing atmosphere leads to a decrease in the valency of the impurity due to recombination of ions with Compton secondary electrons (or reduction) [2].

Figure 1c shows changes in the absorption of Er:YAP and Nd:YAP crystals after gamma irradiation with the same dose $10^{5}$ Gy (curves 1 and 2) and changes after proton irradiation with a fluency of $10^{15}$ protons $/ \mathrm{cm}^{2}$ for Er:YAP crystal (curve 3). Clearly, all the changes ase of the same type, i.e. the appearance of CC is of the same type.

Figure 2 shows the absorption $(K)$ and changes in the absorption $\left(\Delta K^{\circ}\right)$ (compare curves 1 and 2) for $\mathrm{Cr}^{4+}\left(\mathrm{Cr}^{4+}: \mathrm{YAG}\right.$ crystal, curve 1) and $\mathrm{Cr}^{3+}$ doped $Y A G$ crystals (after annealing of $\mathrm{Cr}^{4+}: Y A G$ crystal in reducing atmosphere). The as-grown $\mathrm{Cr}^{4+}$ :YAG crystal was black in color, while the $\mathrm{Cr}^{3+}$ :YAG one was green. As is seen from a.bsorption curves both crystals contain a dopant of second lype $\left(\mathrm{Cr}^{4+}\right.$ :YAG crystal contains also $\mathrm{Cr}^{3+}$ and $\mathrm{Cr}^{3+}$ :YAG crystal contains also $\mathrm{Cr}^{4+}$ ). The dashed lines mark the positions of absorption bands characteristic of a given type of the active dopant.

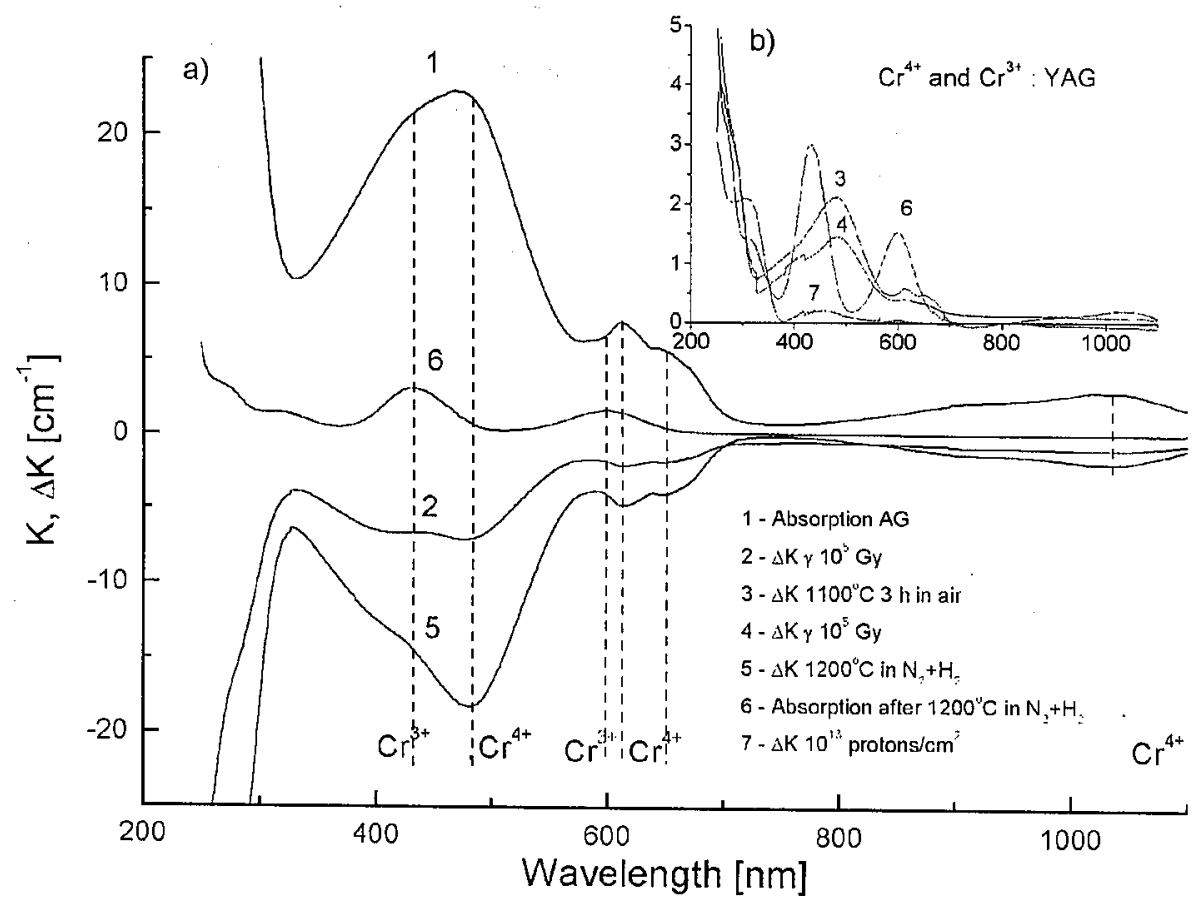

Fig. 2. (a), (b) Absorption (curves 1 and (5) and additional absorption (curves 2-5 and 7) of $\mathrm{Cr}^{4+}$ doped YAG crystal after subsequent treatments: (2) $\gamma$-irradiation with a dose of $10^{5} \mathrm{~Gy},(3)$ annealing at $1100^{\circ} \mathrm{C}$ in air for $3 \mathrm{~h}$, (4) $\gamma$-irradiation with the same dose as previously, (5) annealing at $1200^{\circ} \mathrm{C}$ in $\mathrm{N}_{2}+\mathrm{H}_{2}$ mixture for $0.5 \mathrm{~h}$, and (7) proton irradiation with a fluency of $10^{12}$ protons $/ \mathrm{cm}^{2} ; A G \equiv$ as grown. 
Thus, $\gamma$-irradiation of as-grown crystal (curve 2) and annealing of the crystal in reducing atmosphere (curve 5) lead to a decrease in concentration of $\mathrm{Cr}^{4+}$ ions, due to ion recombination effect $\left(\mathrm{Cr}^{4+} \rightarrow \mathrm{Cr}^{3+}\right)$ and reduction, respectively. Annealing in air (curve 3 ) and subsequent $\gamma$-irradiation (curve 4) lead to an increase in $\mathrm{Cr}^{4+}$ ions concentration due to the ionization effect $\left(\mathrm{Cr}^{3+} \rightarrow \mathrm{Cr}^{4+}\right)$. However, the explanation of proton interactions with crystals is more complicated. After annealing of the crystal in the reducing atmosphere (when majority of $\mathrm{Cr}$ ions are trivalent), protons interact similarly as gamma quanta, producing more $\mathrm{Cr}^{3+}$ ions due to $\delta$-electrons emitted along the proton trajectory. As mentioned above, some amount of $\mathrm{Cr}^{4+}$ ions exists in the $\mathrm{Cr}^{3+}$ :YAG crystal. These $\mathrm{Cr}^{4+}$ ions recombine with $\delta$-electrons in the same way as secondary electrons created by gamma rays in Compton process.

In the case of chromium doped YAG crystals we observed mainly recharging processes of chromium ions. Akhmadulin et al. [5] showed that depending on the applied annealing process of YAG crystals (annealing in oxidizing or reducing atmosphere) $\gamma$-irradiation may produce two different types of defects: $V_{0}$-type vacancies and $\mathrm{O}^{-}$-type holes (the band with a peak at $385 \mathrm{~nm}$ ) in a crystal annealed in an oxidizing atmosphere, while the $\mathrm{F}^{-}$centers in a crystal annealed in a reducing atmosphere.

Figure $3 \mathrm{a}$ shows changes in absorption spectra $(\Delta K)$ after two types of annealing treatments for $\mathrm{Ce}: \mathrm{Y}_{3} \mathrm{Al}_{5} \mathrm{O}_{12}$ (Ce:YAG) single crystal. Clearly, the influence of both types of annealing is opposite to each other (curves 1 and 2). Moreover,

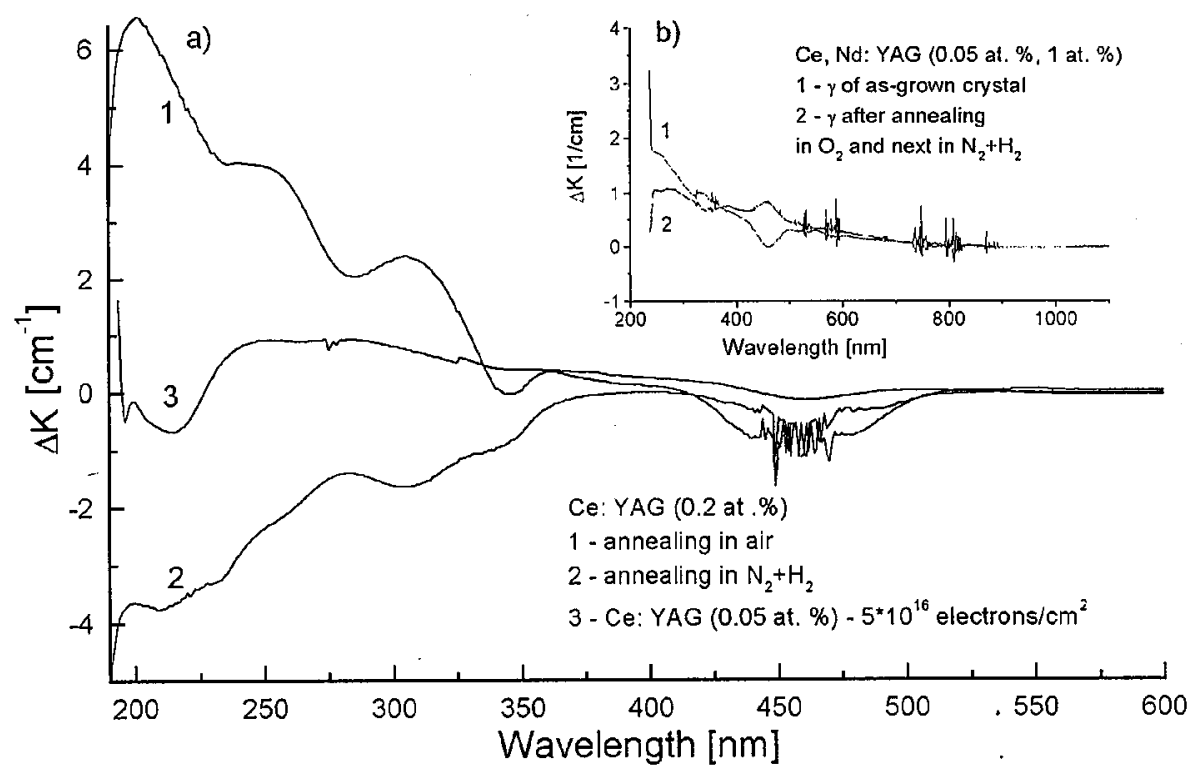

Fig. 3. AA bands in (a) Ce:YAG (0.2 at. \% and 0.05 a.t. \%) single crystäls after different types of annealing procedures (curves 1 and 2) and electron irradiation with a fluency of $5 \times 10^{16} \mathrm{~cm}^{-2}$ (curve 3) and in Ce, Nd:YAG (0.05 at. \% and 1 at. \%), (b) after $\gamma$-irradiation with a dose of $10^{5} \mathrm{~Gy}$. 
the recharging effect is seen for $\mathrm{Fe}^{3+}$ (a band centered at $253 \mathrm{~mm}$ ) and $\mathrm{Ce}^{3+}$ (bands centered at 338 and $458 \mathrm{~nm}$, Fig. $3 \mathrm{a}$ and Fig. $3 \mathrm{~b}$ ) ions. Radiation can influence the absorption in opposite way depending on the previous annealing treatment for irradiated crystal, as seen in Fig. 3 b (curves 1 and 2). Electrons interact with active (Ce) and uncontrolled ( $\mathrm{Fe}$ ) ions recharging them as is seen in Fig. 3a (curve 3). The Ce:YAG crystal doped with a high concentration of Ce $(0.2$ at. \%) is strongly defected.

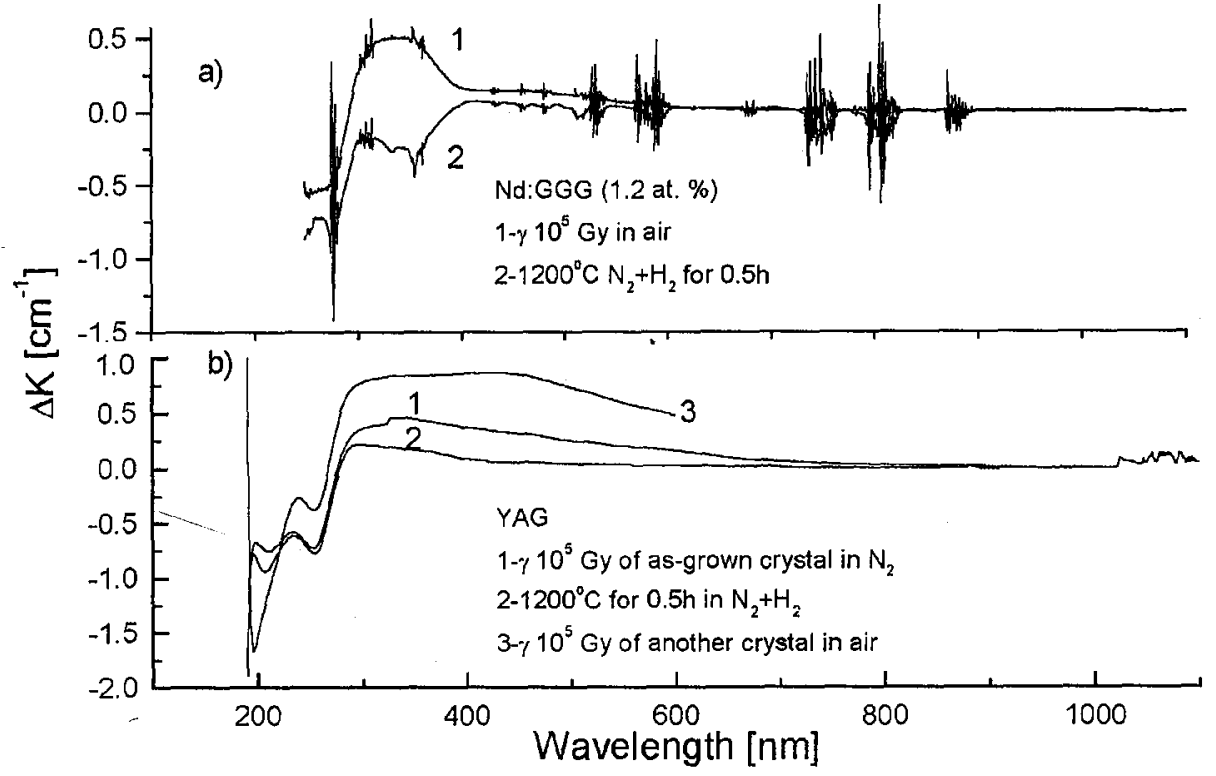

Fig. 4. AA bands in (a) Nd:GGG and (b) YAG single crystals after $\gamma$-irradiation (curve 1 in (a) and curve 1 and 3 in (b)) as compared to annealing in reducing atmosphere (curve 2 in (a) and curve 2 in (b)).

Figure 4 presents changes in absorption spectrum of (a) Nd:GGG and (b) pure YAG single crystals under irradiation with $\gamma$-rays as compared to annealing in reducing atmosphere (after annealing of $\mathrm{Nd}$ :GGG crystal in reducing atmosphere secondary polishing was necessary). As seen from Fig. 4, if no oxide vacancies are present in a crystal, the AA bands (which appear in the absorption spectra of the crystals after treatment with $\gamma$-rays and annealing in reducing atmosphere) have the same shape (see curves 1 and 2, Fig. 4 b and, for comparison, curves 1 and 2, Fig. 4a). The oxygen vacancies in YAG crystal are seen as CC with a weak maximum at about $450 \mathrm{~nm}$ (see curve 3, Fig. 4b), while in GGG crystal the oxygen vacancies are seen as $C C$ with a maximum at about $340 \mathrm{~nm}$.

Figure 5 shows the changes in the absorption spectrum of $\mathrm{LiNbO}_{3}$ single crystal doped with (a) 1 at. \% Dy and (b) 0.03 at. \% Er after $\gamma$-irradiation with a dose of $10^{5} \mathrm{~Gy} \cdot \mathrm{LiNbO}_{3}$ single crystals are in general less affected by gamma or proton irradiation than YAP, SLGO, YAG, or GGG crystals. Thus, the additional absorption is only $0.4 \mathrm{~cm}^{-1}$ in contrast to other crystals where this may be equal to even $25 \mathrm{~cm}^{-1}$ (see, for example, Fig. 1a). 


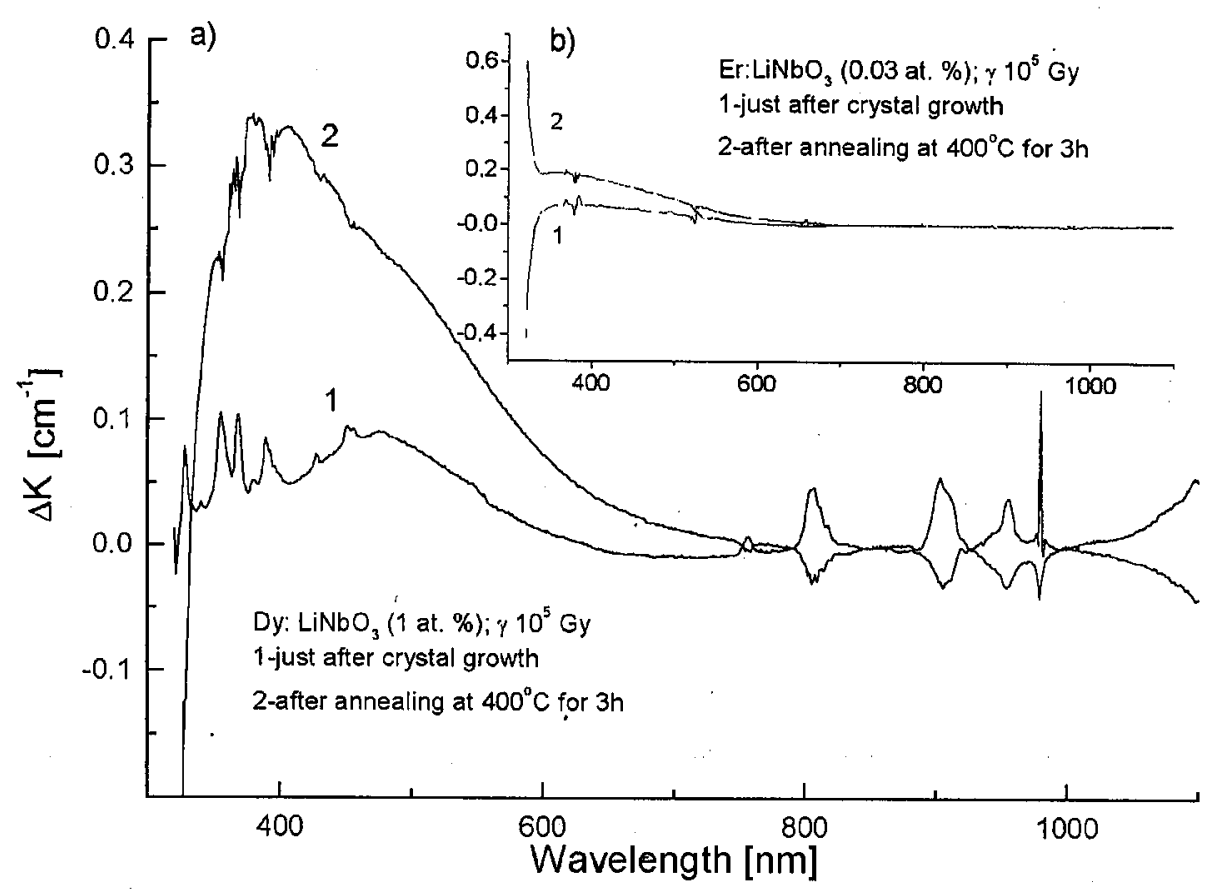

Fig. 5. AA bands in (a) Dy doped and (b) Er doped $\mathrm{LiNbO}_{3}$ single crystals after $\gamma$-irradiation treatment before and after annealing in air at $400^{\circ} \mathrm{C} .1$ - just after crystal growth, 2 - after annealing at $400^{\circ} \mathrm{C}$ for $3 \mathrm{~h}$.

As may be seen from Fig. 5, for a crystal which is thermally unstable, $\gamma$-irradiation of the previously annealed crystal gives greater values for AA intensity than that for as-grown crystal. One of the possible reason of this behavior may be that annealing of $\mathrm{LN}$ crystals was performed at a relatively low temperature.

Arizmendi et al. [6] have shown that annealing and irradiation create different defects in $\mathrm{LiNbO}_{3}$ crystal. In both types of treatments, polarons of energy of $1.6 \mathrm{eV}$ were observed. In the case of irradiated crystals trapped holes and in the case of reduced crystals $\mathrm{F}$ and $\mathrm{F}^{+}$centers were observed.

In Fig. 5a recharging process of dysprosium ions is also seen for $\mathrm{Dy}^{3+}: \mathrm{LN}$ crystal (see changes in absorption spectrum for wavelengths greater than $800 \mathrm{~nm}$ ). This suggests that $\mathrm{Dy}^{2+}$ ions are probably present in the as-grown crystals [7].

\subsection{Luminescence}

Figure 6 shows absorption (curve 1), additional absorption after $\gamma$-irradiation with a dose of $10^{5}$ Gy (curve 2), and $10^{6} \mathrm{~Gy}$ (curve 3) and luminescence after this irradiation (curve 4) observed for LiF single crystal. After $\gamma$-irradiation of as-grown $\mathrm{LiF}$ crystal, CC's peaks appear at $259,329,385,455$, and $550 \mathrm{~nm}$. The band at $455 \mathrm{~nm}$ is attributed to the $\mathrm{F}_{2}$ center, $[-|2 e|]$, while the band at $550 \mathrm{~nm}$ is attributed to the $\mathrm{F}^{2+}$ center, $[-|e|][8]$. The intensity of AA related to these CC's 


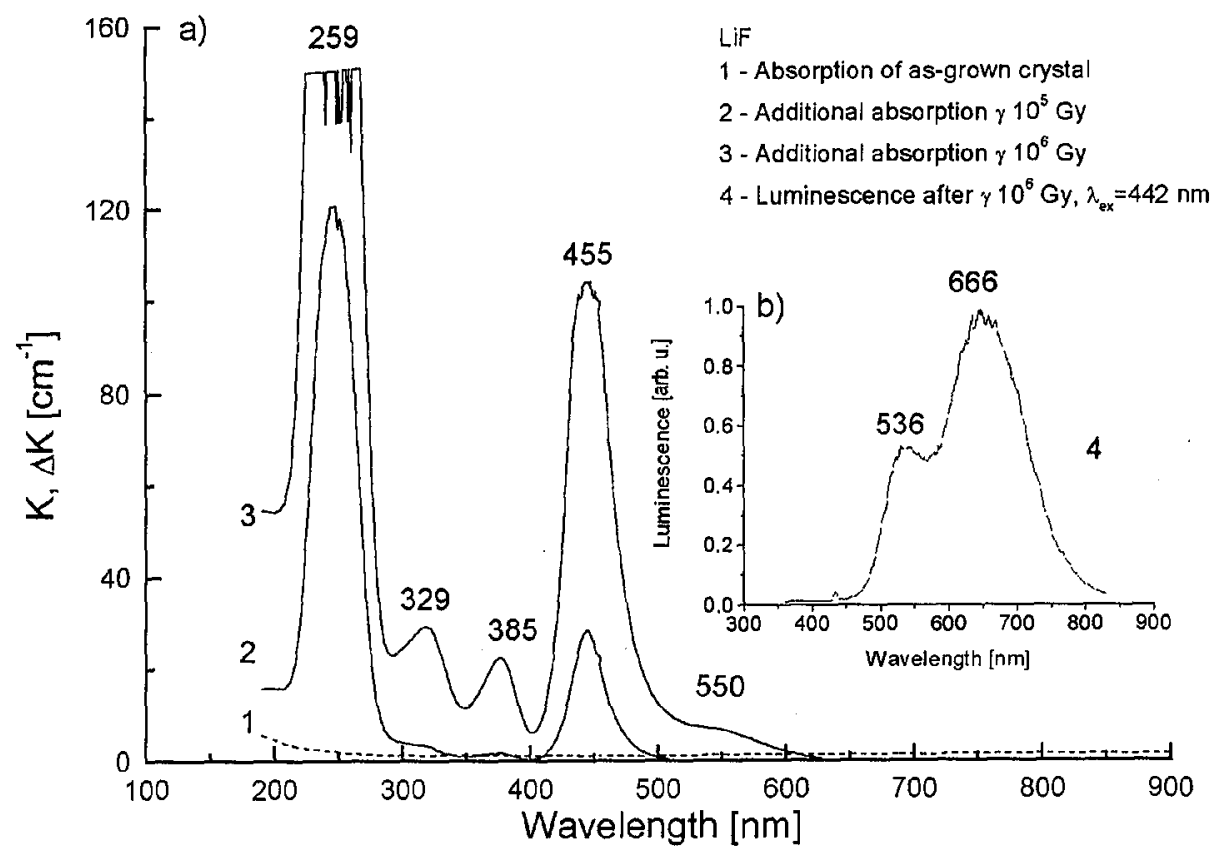

Fig. 6. (a) Absorption (curve 1), additional absorption after $\gamma$-irradiation with a dose of $10^{5} \mathrm{~Gy}$ (curve 2), additional absorption after $\gamma$-irradiation with a dose of $10^{6} \mathrm{~Gy}$ (curve 3 ) and (b) excited with $442 \mathrm{~nm}$ photoluminescence of LiF single crystal (curve 4).

is much greater than that for other crystals (e.g. for $259 \mathrm{~nm}$ band it is as high as $160 \mathrm{~cm}^{-1}$ ). It depends also on the dose value (compare curves 2 and 3 ), moreover, for $\gamma$-irradiated crystals strong emission at 536 and $664 \mathrm{~nm}$ is found after exciting the crystal with $\lambda_{\text {ex }}=442 \mathrm{~nm}$ (laser excitation). Exciting with $455 \mathrm{~nm}$ gives two bands equal in intensity, while exciting with $385 \mathrm{~nm}$ gives much higher intensity of $536 \mathrm{~nm}$ band in comparison to 664 one. CC's in LiF crystal are often applied as $Q$-switches in laser systems [9]. Such a behavior of the crystals suggests that ionizing radiation can radically change optical properties of a crystal.

Figure 7 presents absorption (curve 1), additional absorption (curve 2) and photoluminescence (curve 3) of $\mathrm{Co}: \mathrm{LaGaO}_{3}$ single crystal. The absorption spectrum shows transitions in $\mathrm{Co}^{2+}$ and $\mathrm{Co}^{3+}$ mixed system seen in the range of VIS and near IR. $\mathrm{Co}^{3+}$ has two excited states of the energies corresponding to visible part of the spectrum, ${ }^{1} T_{1}$ (about $667-769 \mathrm{~nm}$ ) and ${ }^{1} T_{2}$ (about $455-500 \mathrm{~nm}$ ) and one in IR (about $1600 \mathrm{~nm}$ ). The as-grown $\mathrm{Co}: \mathrm{LaGaO}_{3}$ crystal does not show any luminescence in the visible range. After $\gamma$-irradiation with a dose of $4 \times 10^{5} \mathrm{~Gy}$ additional absorption bands appear with maxima at 450,540 , and $680 \mathrm{~nm}$. They can be attributed to $\mathrm{Co}^{3+}$ ions arising due to the ionization of $\mathrm{Co}^{2+}$ ions present in the as-grown crystal, as is seen from the absorption curve. Excitation with $\lambda_{\text {ex }}=442 \mathrm{~nm}$ gives strong luminescence of these ions with a peak at about $650 \mathrm{~nm}$. This behavior suggests that $\gamma$-irradiation can dramatically change the emission properties of the crystal. 


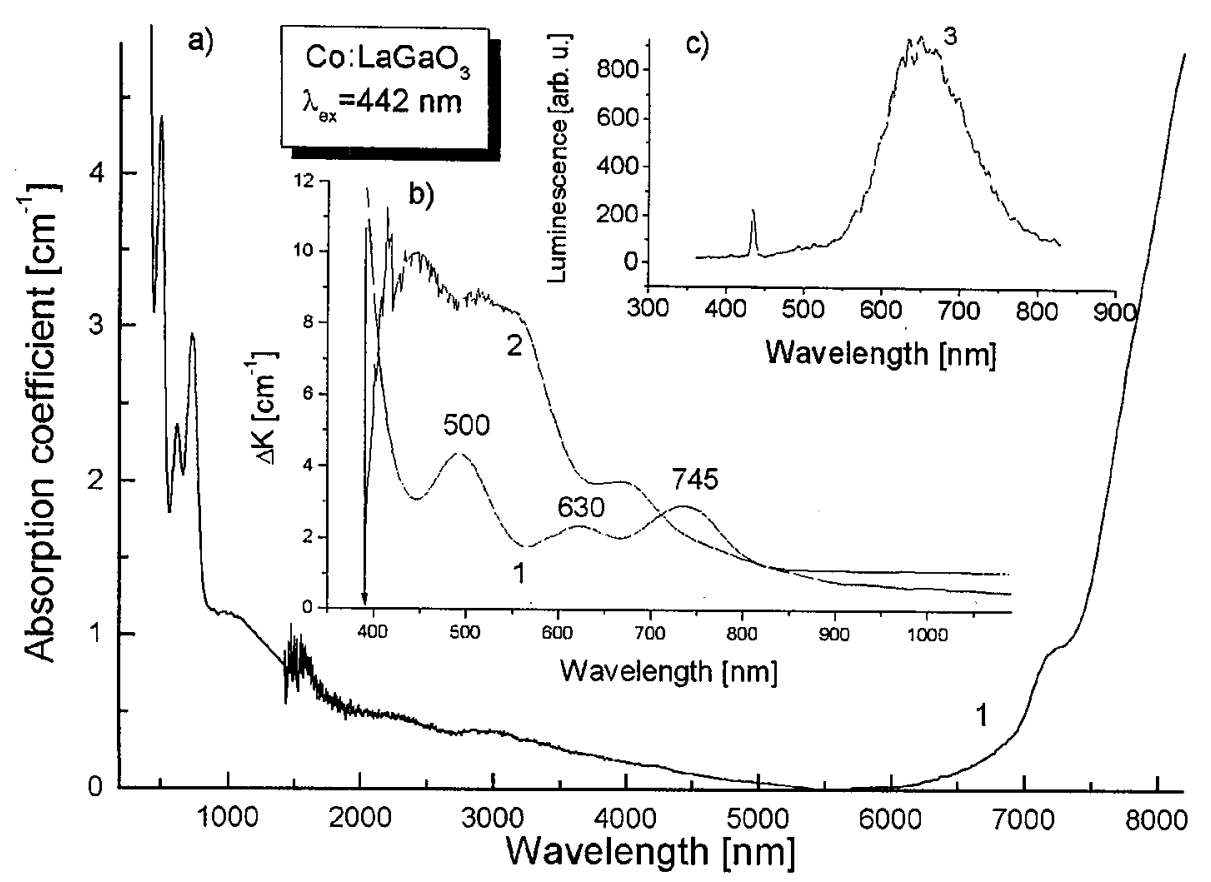

Fig. 7. (1) Absorption of as-grown crystal in the range $200-8000 \mathrm{~nm}$, (2) additional absorption in the range $200-1100 \mathrm{~nm}$, and (3) photoluminescence in the range $350-850 \mathrm{~nm}$ of $\gamma$-irradiated $\mathrm{Co}: \mathrm{LaGaO}_{3}$ single crystal (dose $4 \times 10^{5} \mathrm{~Gy}$ ).

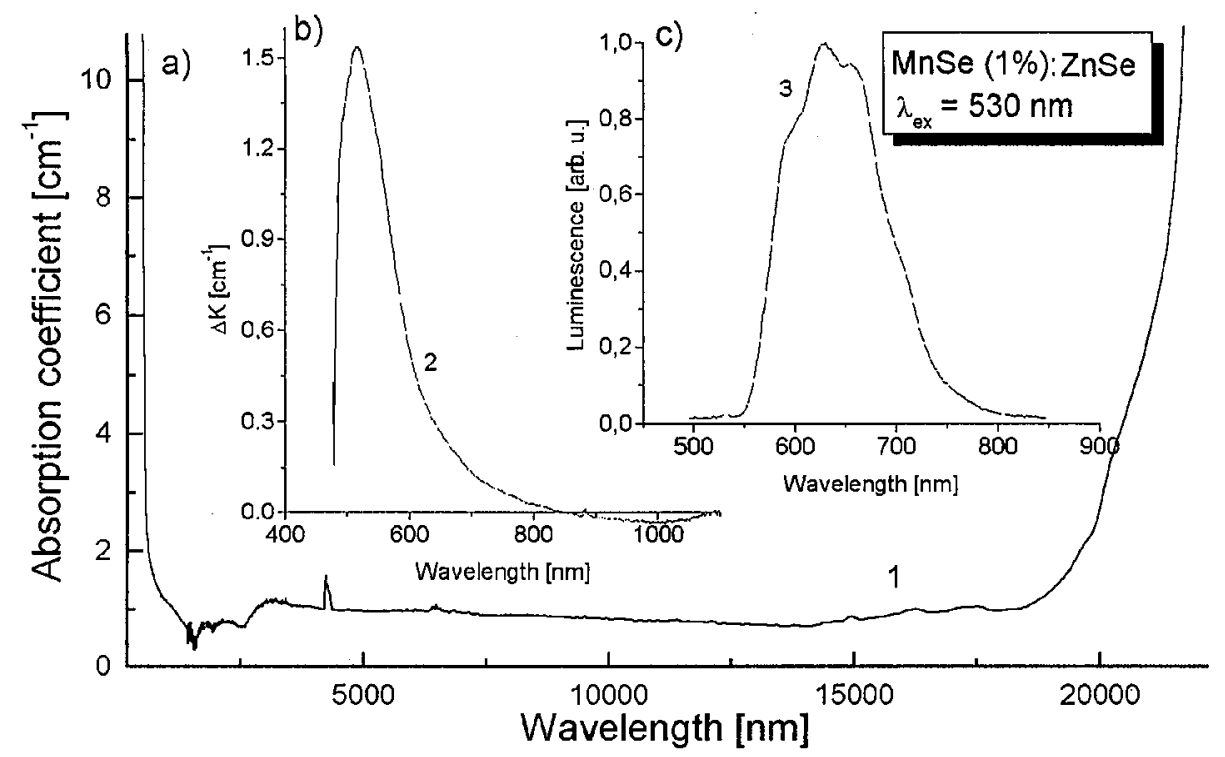

Fig. 8. (a) Absorption (curve 1), (b) additional absorption after $\gamma$-irradiation with a dose of $4 \times 10^{5}$ Gy (curve 2) and (c) photoluminescence (curve 3) of $\mathrm{MnSe}(1 \%): \mathrm{ZnSe}$ single crystal. 
ZnSe single crystal codoped with $1 \%$ MnSe exhibits a similar behavior (Fig. 8). The absorption spectrum of $\mathrm{Mn}: \mathrm{ZnSe}$ crystal does not show any electron transition bands in the range from 200 to $20000 \mathrm{~nm}$ (curve 1). After $\gamma$-irradiation with a dose of $4 \times 10^{5} \mathrm{~Gy}$ an additional absorption band appears at $520 \mathrm{~nm}$, which is connected probably with $\mathrm{Mn}^{3+}$ ions created by gamma ionization of $\mathrm{Mn}^{2+}$ ions (curve 2). Luminescence of the crystal with green light $\left(\lambda_{\mathrm{ex}}=530 \mathrm{~nm}\right)$, seen after gamma irradiation, has a maximum at about $650 \mathrm{~nm}$ (see Fig. 8b, curve 3 ).

All crystals, whose optical characteristics are presented in Figs. 6-8, exhibit strong red luminescence at about $650 \mathrm{~nm}$, but only in the case of LiF crystals it is due to CC. Other crystals show also new luminescence bands connected with the creation of new types of active dopants coming from recharged active ions ( $\mathrm{Co}^{3+}$ and $\mathrm{Mn}^{3+}$ ).

\section{Conclusions}

Generally, annealing in air leads to an increase in valency of uncontrolled or active impurity ( $\mathrm{Cr}^{3+}: \mathrm{YAG}$ ), while $\gamma$-irradiation (or annealing in reducing atmosphere) ( $\left.\mathrm{Cr}^{4+}: Y A G\right)$, due to ion recombination with secondary Compton electrons (or reduction), leads to a decrease in valency (Fig. 2) [2]. However, there are some ions, which are ionized by gamma quanta ( $\left.\mathrm{Cr}^{3+}: \mathrm{YAG}\right)$ due to the Compton interaction. In particular case recharging depends on a previous treatment, local symmetry of ion, and crystal field. Protons can also interact similarly as gamma rays. The only difference in the mechanisms of their interaction with oxide crystals is the source of secondary electrons, or ionization mechanism.

Different treatments (annealing in reducing or oxidizing atmospheres, irradiation) produce different characteristic defects. They may be CC's, such as $\mathrm{F}, \mathrm{F}^{+}, \mathrm{F}^{-}, \mathrm{F}^{2+}, \mathrm{F}^{2-}$, polarons, trapped holes [6], AA bands attributed to recharged dopants $\left(\mathrm{Ce}^{3+}, \mathrm{Cr}^{3+}, \mathrm{Dy}^{3+}, \mathrm{Nd}^{3+}\right)$, or uncontrolled ions $\left(\mathrm{Mn}^{2+}[10]\right.$, $\left.\mathrm{Fe}^{3+}, \mathrm{Fe}^{2+}\right)$. Effects of gamma irradiation performed for the same crystial, previously annealed in different manner, can be of opposite sign (see Fig. 3).

If a crystal does not contain the oxygen vacancies, the AA bands after both types of treatments, i.e. gamma rays and annealing in reducing atmosphere, have the same shape (Fig. 4).

The level of crystal defecting after irradiation depends strongly on its initial quality and also on concentration of active dopant. The quantity of point defects, which may be recharged due to ionizing irradiation, is for the investigated crystals of the order of $10^{17} \mathrm{~cm}^{-3}$ [2]. Also annealing at too low temperatures can create new defects (Fig. 5).

For $\gamma$-rays with energies $\approx 1.25 \mathrm{MeV}$ recharging processes, due to the Compton effect and ionization of active ions, were mainly observed.

For electrons with energies $<1 \mathrm{MeV}$ (doses $10^{14}-10^{16} \mathrm{~cm}^{-2}$ ) ionizing processes of active ions were dominant.

For dose of protons $<10^{14} \mathrm{~cm}^{-2}$ mainly recombination with delta electrons takes place, while for doses of protons $>10^{14} \mathrm{~cm}^{-2}$ Frenkel defects also arise (whose quantity increases linearly with the dose [4]). The latter effect is caused by nuclear scattering of protons. 
Changes in luminescence spectrum after gamma irradiation were observed in $\mathrm{LiF}, \mathrm{Co}: \mathrm{LaGaO}_{3}$, and $\mathrm{Mn}: \mathrm{ZnSe}$ single crystals (Figs. 6-8). Such behavior indicates that $\gamma$-irradiation can dramatically change emission properties of the crystals.

Thus, irradiation and annealing treatments appear to be the effective tools for characterization and alteration of properties of oxide single crystals.

\section{Acknowledgments}

The authors wish to thank Profs. M. Demianiuk, T. Łukasiewicz, Dr. A. Majchrowski, Mrs. I. Pracka, and Mr Z. Frukacz for preparation of crystals for investigations.

\section{References}

[1] T.S. Rose, M.S. Hopkins, R.A. Fields, IEEE J. Quantum Electron. 31, 1593 (1995).

[2] A.O. Matkovskii, D.J. Sugak, A.N. Durygin, S.M. Kaczmarek, K. Kopczyński, Z. Mierczyk, Z. Frukacz, T. Łukasiewicz, A.P. Shakhov, Opt. Mater. 6, 353 (1996). See also: A.O. Matkovskii, D.J. Sugak, S.B. Ubizskii, O.I. Shpotiuk, E.A. Chernyi, N.M. Vakiv, V.A. Mokshyckii, Vozdestvie ioniziruyushchikh izluchenij na materialy elektronnoy tekhniki, Svit, Lvov 1994, p. 132.

[3] S.M. Kaczmarek, W. Żendzian, T. Łukasiewicz, K. Stępka, Z. Moroz, S. Warchoł, Spectrochim. Acta A 54, 209 (1998).

[4] S.M. Kaczmarek, R. Jabłoński, I. Pracka, G. Boulon, T. Eukasiewicz, Z. Moroz, S. Warchoł, Nucl. Instrum. Methods Phys. Res. B 142, 515 (1998). See also: S.M. Kaczmarek, J. Kisielewski, R. Jabłoński, Z. Moroz, M. Kwaśny, T. Eukasiewicz, S. Warchoł, J. Wojtkowska, Biul. WAT 7/8, 113 (1998).

[5] I.Sh. Akhmadulin, S.A. Migachev, S.P. Mironov, Nucl. Instrum. Methods Phys. Res. B 65, 270 (1992).

[6] L. Arizmendi, J.M. Cabrera, F. Agullo-Lopez, J. Phys. C, Solid State Phys. 17, 515 (1984).

[7] S.M. Kaczmarek, T. Łukasiewicz, I. Pracka, R. Jabłoński, G. Boulon, B. Kaczmarek, S. Warchoł, J. Alloys Comp. 275-277, 105 (1998).

[8] J.L. Gusev, S.I. Marennikov, C.J. Novozilov, K'vantova Elektronika 5, 1685 (1978).

[9] Z. Mierczyk, J. Czeszko, S.M. Kaczmarek, Biul. WAT 3, 95 (1986).

[10] S.M. Kaczmarek, R. Jabłoński, I. Pracka, M. Świrkowicz, J. Wojtkowska, S. Warchoł, Cryst. Res. Technol. 34, 729 (1999). 